\title{
The esthetic surgical management of a submandibular fascial space infection of odontogenic origin
}

\author{
Cristian Rotaru ${ }^{1,2}$, Iulian Filipov ${ }^{1}$, Lucian Chirilă ${ }^{1,3}$, Mihai Săndulescu ${ }^{2,3^{*}}$ \\ From The 10th Edition of the Scientific Days of the National Institute for Infectious Diseases "Prof Dr Matei \\ Bals" \\ Bucharest, Romania. 15-17 October 2014
}

\section{Background}

Odontogenic infections are common complications in dental practice and can sometimes spread through the cervical fascia and cause abscesses of the deep fascial spaces. Some of these abscesses can be life threatening. Early diagnosis of these deep fascial abscesses and aggressive antimicrobial and surgical treatment with extensive drainage are of utmost importance. The aim of this presentation is to show the clinical characteristics of a submandibular fascial space abscess and its esthetic, minimally-invasive surgical management.

\section{Case report}

We present two cases of submandibular space abscesses that underwent surgical treatment using an esthetic incision with a through-and-through suction drainage of the pus collection, unidirectional lavage and intravenous antibiotics. This technique is best suited for young patients with esthetic requirements and with abscesses located in only one fascial space. However, using the esthetic approach, one must follow the same principles of the surgical treatment as for the classical incision: complete evacuation of pus, creating and maintaining a good postsurgical drainage. If these principles cannot be accomplished, classical incision must be considered.

\section{Conclusion}

Because of the anatomical location of such abscesses in the facial and cervical areas, classical surgical management and debridement is, in some instances, unacceptable by

* Correspondence: mihai.s@gmail.com

2Dental Concept Studio, Bucharest, Romania

Full list of author information is available at the end of the article the patient, and classical extensive drainage is not easy to achieve.

\section{Authors' details}

"'Dan Theodorescu" Clinical Hospital of Oral and Maxillo-Facial Surgery, Bucharest, Romania. ${ }^{2}$ Dental Concept Studio, Bucharest, Romania. ${ }^{3}$ Carol Davila University of Medicine and Pharmacy, Bucharest, Romania.

Published: 15 October 2014

doi:10.1186/1471-2334-14-S7-P69

Cite this article as: Rotaru et al:: The esthetic surgical management of a submandibular fascial space infection of odontogenic origin. $B M C$ Infectious Diseases 2014 14(Suppl 7):P69.
Submit your next manuscript to BioMed Central and take full advantage of:

- Convenient online submission

- Thorough peer review

- No space constraints or color figure charges

- Immediate publication on acceptance

- Inclusion in PubMed, CAS, Scopus and Google Scholar

- Research which is freely available for redistribution
() Biomed Central 